\title{
Lymphocyte subpopulations in patients with multiple sclerosis
}

\author{
ALASTAIR COMPSTON
}

From the Institute of Neurology, Queen Square, London, UK

SUMMARY Using monoclonal antibodies, peripheral blood helper/inducer (OKT4) and cytotoxic/ suppressor (OKT8) lymphocytes were measured in 14 normal controls, 36 patients with multiple sclerosis at different stages of the disease and 15 patients with isolated optic neuritis. Thirty-four of these individuals were studied on two or more occasions at intervals up to 340 days. Patients with multiple sclerosis in relapse had low levels of OKT8 cells $(14.07 \% \pm 3.79)$ compared with controls $(29.42 \% \pm 4.69)$ and this abnormality returned to normal within approximately one month of the onset of new symptoms. Further changes occurred with new relapses. Low OKT8 cells were also found in patients with isolated optic neuritis $(18 \cdot 76 \pm 3 \cdot 71)$ or progressive multiple sclerosis $(19 \cdot 91 \% \pm 7 \cdot 96)$; the same pattern of recovery was seen in these two groups as in patients with multiple sclerosis in relapse. In $25 \%$ patients studied on two or more occasions after an episode of demyelination abnormalities of lymphocyte subpopulations occurrèd which were not accompanied by new clinical symptoms or signs. Fluctuations of this kind did not occur in controls. The findings have implications for the pathogenesis and management of patients with multiple sclerosis.

Factors which precipitate relapses in patients with multiple sclerosis are poorly understood. Evidence for immunologically mediated tissue damage in multiple sclerosis includes the presence of oligoclonal immunoglobulin (Ig) in the central nervous system (CNS) and increased frequency of certain HLA antigens but neither abnormality correlates with activity of the disease. Although there is no consistent evidence for antigen specific abnormalities of antibody production or cellular re-activity in peripheral blood of patients with multiple sclerosis ${ }^{12}$ the presence of changes in number or ratio of circulating lymphocyte subpopulations which generate immune responses may reflect alterations in immune regulation even if their specificity is unknown.

There is a deficiency of total $\mathrm{T}$ cells in peripheral blood and excess in cerebrospinal fluid (CSF) particularly in patients with active disease. ${ }^{3-5}$ Active $T$ lymphocytes and $T_{G}$ cells (those forming early sheep red cell and IgG sensitised ox red blood cell rosettes, respectively), are reduced in peripheral blood and CSF during periods of disease activity. ${ }^{-10}$ More recent studies using commercially available OKT

\footnotetext{
Address for reprint requests: Dr A Compston, Department of Neurology, University Hospital of Wales, Heath Park, Cardiff, CF4 4XW, UK.

Received 3 September 1982

Accepted 4 October 1982
}

monoclonal antibodies raised against human lymphocyte subpopulations show a significant increase in ratio of OKT $4: 8$ cells during relapse and in progressive cases, but not in patients with stable multiple sclerosis, other neurological diseases or normal controls. This change is due to a decrease in OKT8 cells since OKT4 cells remain unchanged. ${ }^{11} 12$ Limited serial studies of active $T$ cells, ${ }^{6} \mathrm{~T}_{\mathrm{G}}$ cells ${ }^{8}$ or OKT4:8 ratio ${ }^{11}$ in ten patients followed through a relapse showed, in nine cases, a fall and return to normal with clinical recovery.

Detailed longitudinal studies in individual patients described in this report illustrate some implications of these changes in peripheral blood during periods of disease activity for management and pathogenesis of multiple sclerosis.

\section{Patients and controls}

Peripheral blood lymphocyte subpopulations were measured on at least one occasion in 65 individuals; Group 1 $(n=14,21 \%)$ consisted of 13 normal controls and one patient with cervical spondylosis; patients with other neurological diseases were not included. In Group 2 there were $11(17 \%)$ cases of clinically definite ${ }^{13}$ multiple sclerosis in relapse. Group $3(n=8,12 \%)$ contained seven patients with acute optic neuritis and one with an isolated brain stem lesion. All eight were suspected cases of multiple sclerosis; the patient with brain stem demyelination had abnormal visual evoked potentials (VEPs) and an oligoclonal CSF 
electrophoretic pattern. One patient with optic neuritis was already known to have clinically definite multiple sclerosis; four others had had previous episodes involving non-visual pathways, the significance of which was uncertain at the time and two developed cervical cord lesions shortly before or after the episode of optic neuritis. Seven of these patients do not fulfill the criteria for clinically definite multiple sclerosis and they have been separated from Group 2 and from Group 4 which consisted of $15(23 \%)$ patients with acute optic neuritis but no evidence of previous or more widespread demyelination. In Group 5 there were 17 (26\%) patients with a fixed or slowly progressive deficit due to multiple sclerosis in whom it was not possible to identify a recent relapse.

The interval between onset of symptoms, in patients with acute episodes, and first blood sample varied from 3-28 days. In order to investigate changes in lymphocyte subpopulations during recovery from acute episodes and remission 34/65 (52\%) individuals from Group 1 (10), Group 2 (9), Group 3 (6), Group 4 (6) and Group 5 (3) were studied on two or more occasions at intervals up to 340 days.

\section{Methods}

Lymphocyte subpopulations were identified by indirect immunofluorescence. Unfractionated lymphocytes were collected by centrifugation of $10 \mathrm{ml}$ peripheral blood over sodium metrizoate/ficoll solution (Lymphoprep), washed twice in phosphate buffered saline (PBS) and suspended in McCoy's culture medium with $0.5 \%$ heat inactivated foetal calf serum at a concentration of $5 \times 10^{6} / \mathrm{ml}$. Two hundred microlitre aliquots were then incubated at $+4^{\circ} \mathrm{C}$ for 30 minutes with $5 \mu \mathrm{l}$ of OKT4 and OKT8 monoclonal antibody (Orthoclone) used neat after reconstitution as directed in 1 $\mathrm{ml}$ of PBS. After two further washes in PBS the cell pellet was re-suspended and incubated at $+4^{\circ} \mathrm{C}$ for 30 minutes with $100 \mu \mathrm{l}$ of fluorescine conjugated goat anti-mouse immunoglobulin at a dilution of 1 in 30 in PBS with $0.5 \%$ foetal calf serum. After two further washes in PBS the cell pellet was re-suspended in one drop of PBS with glycerine. Fluorescent and total cells were counted visually in a minimum of three areas on a haemocytometer grid under water immersion. After background subtraction using fluorescine conjugated goat anti-mouse immunoglobulin incubated cells without prior monoclonal OKT antibody incubation the percentage of fluorescent cells in each sample was calculated. All samples were kept at $+4^{\circ} \mathrm{C}$ and counted within 120 minutes of completed second antibody incubation.

\section{Statistics}

Mean values and standard deviations for each group are quoted in the text and tables; non-parametric statistics were used for analysis because of the differing variances. The differences between groups were compared by the Mann Whitney $U$ test and the Kruskal Wallis one-way analysis of variance using the SPSS version $7 \cdot 0$ programme on London University CDC 6600 computer.

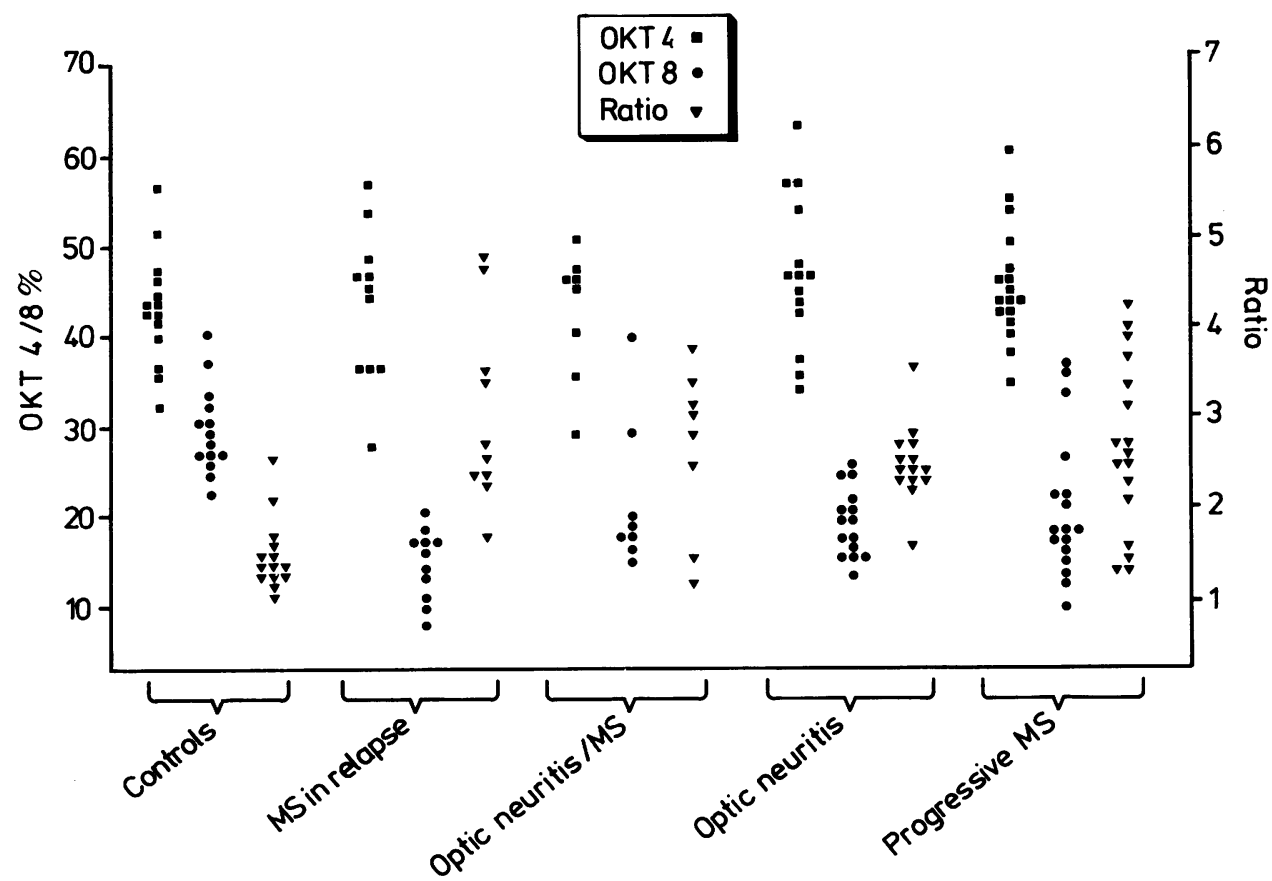

Fig 1 Numbers of OKT4( $\mathbf{\square}), O K T 8(0)$ cells and $O K T 4: 8$ ratio $(\nabla)$ in all individuals from Groups 1-5. Mean values for each group with the standard deviations are shown in table 1. 
Table 1 Statistical significance of comparisons between mean numbers (\%) of OKT4 and 8 lymphocytes in patients with multiple sclerosis (MS) and controls

\begin{tabular}{|c|c|c|c|c|c|}
\hline & $\begin{array}{l}\text { Group } 1 \\
\text { (Normal controls) }\end{array}$ & $\begin{array}{l}\text { Group } 2 \\
\text { (MS in relapse) }\end{array}$ & $\begin{array}{l}\text { Group } 3 \\
\text { (Optic neuritis/MS) }\end{array}$ & $\begin{array}{l}\text { Group } 4 \\
\text { (Optic neuritis) }\end{array}$ & $\begin{array}{l}\text { Group } 5 \\
\text { (Progressive MS) }\end{array}$ \\
\hline $\begin{array}{l}\text { Number } \\
\text { Mean } \pm \text { SD's }\end{array}$ & $14(21 \%)$ & $11(17 \%)$ & $8(12 \%)$ & $15(23 \%)$ & $17(26 \%)$ \\
\hline $\begin{array}{l}\text { OKT4 } \\
\text { OKT8 } \\
\text { Ratio }\end{array}$ & $\begin{array}{r}43 \cdot 87 \pm 7 \cdot 10 \\
29 \cdot 42 \pm 4 \cdot 69 \\
1 \cdot 53 \pm 0 \cdot 40\end{array}$ & $\begin{array}{r}42.93 \pm 9.06 \\
14.07 \pm 3.79 \\
3.39 \pm 1.67\end{array}$ & $\begin{array}{r}46 \cdot 80 \pm 8 \cdot 41 \\
20 \cdot 44 \pm 8 \cdot 86 \\
2 \cdot 58 \pm 0 \cdot 91\end{array}$ & $\begin{array}{r}45 \cdot 90 \pm 8 \cdot 63 \\
18 \cdot 76 \pm 3.71 \\
2 \cdot 45 \pm 0.46\end{array}$ & $\begin{array}{r}45.54 \pm 6.37 \\
19.91 \pm 7.96 \\
2.60 \pm 0.96\end{array}$ \\
\hline \multicolumn{6}{|l|}{$P$ values } \\
\hline Group 1 OKT4 & 一 & 0.95 & $0 \cdot 34$ & 0.42 & $0 \cdot 50$ \\
\hline OKT8 & - & 0.00001 & 0.014 & 0.00001 & 0.0014 \\
\hline Ratio & - & 0.0002 & 0.018 & 0.0001 & 0.0017 \\
\hline Group 2 OKT4 & & - & $0 \cdot 48$ & 0.51 & 0.69 \\
\hline OKT8 & & - & 0.09 & 0.0118 & 0.0384 \\
\hline Ratio & & - & 0.508 & 0.25 & $0 \cdot 26$ \\
\hline Group 3 OKT 4 & & & - & $0 \cdot 81$ & $0 \cdot 64$ \\
\hline OKT8 & & & - & 0.698 & 0.907 \\
\hline Ratio & & & - & 0.305 & 0.907 \\
\hline Group 4 OKT4 & & & & - & $0 \cdot 69$ \\
\hline OKT8 & & & & - & 0.777 \\
\hline Ratio & & & & - & 0.605 \\
\hline
\end{tabular}

Table 2 values for comparing mean numbers (\%) of $O K T 4$ and 8 cells between combined groups of patients with multiple sclerosis and controls

\begin{tabular}{llll}
\hline & OKT4 & OKT8 & OKT4:8 ratio \\
\hline Group 1 vs Groups 2 and 3 & 0.64 & $0 \cdot 00001$ & $0 \cdot 0002$ \\
Group 1 vs Groups 3 and 4 & 0.31 & 0.00001 & $0 \cdot 0001$ \\
Groups 2 and 3 vs Group 4 & 0.76 & 0.058 & $0 \cdot 185$ \\
Group 2 vs Groups 3 and 4 & 0.43 & 0.01 & $0 \cdot 268$ \\
Overall comparison between & 0.8451 & 0.00001 & 0.0005 \\
\hline Groups 1-5 & & & \\
\hline
\end{tabular}

\section{Results}

The results of the first, or only, measurement of OKT4 and OKT8 cells (\%) and the OKT4:8 ratio for all individuals in each group are shown in fig 1 and tables 1,2 . No significant differences in OKT4 cells were found between groups analysed separately or in various combinations.

There was a significant reduction in OKT8 cells in patients compared to controls $(\mathrm{p}=0.00001)$ in whom the mean level $(\%)$ was $29 \cdot 42 \pm 4 \cdot 69$. The lowest values were obtained in Group 2 (mean 14.07\% \pm 3.79) with intermediate results in Group 3 (mean $20.44 \% \pm 8.86)$, Group $4(18.76 \% \pm 3.71)$ and Group $5(19.91 \% \pm 7.96)$. The difference between Group 2 and Group 4 or 5 but not Group 3, was significant ( $p=0.0118,0.038$ and 0.09 respectively). All other comparisons within patients (Groups 2-5) showed no significant differences. As expected the combination of all patients with definite or suspected multiple sclerosis (Groups 2 and 3) or all patients with optic neuritis from Groups 3 and 4 remained significantly different from controls ( $p=0.00001$ in each case). Combining Group 3 with either Group 2 or 4 showed that lower values of OKT8 cells were found in patients with relapses affecting non-visual pathways than in patients with optic neuritis whether this was known to be a manifestation of multiple sclerosis or not.

The decreases in OKT8 cells were in general reflected by increases in OKT4:8 ratio in patients compared to controls $(p=0.0005)$ in whom the mean ratio was $1.53 \pm 0.40$. The highest ratios were seen in Group $2(3.39 \pm 1.67)$ with intermediate increases in Group $3(2.58 \pm 0.91)$, Group $4(2.45 \pm 0.46)$ and Group $5(2.60 \pm 0.96)$. None of the differences in ratio between groups of patients was significant. Combinations of patients with definite or suspected multiple sclerosis (Group 2 and 3 ) or patients with optic neuritis from Group 3 and 4 remained significantly different from controls. No significant differences between patients with demyelination affecting visual and non-visual pathways were obtained by comparing Groups 2, 3 and 4 in different combinations.

\section{Longitudinal studies in controls}

Lymphocyte subpopulations were studied on more than one occasion in 10 normal controls at random intervals of approximately six weeks for up to 340 days (fig 2). There was very little variation within or between individuals in OKT8 cells and although OKT 4 cells were less stable this did not result in wide fluctuations of the OKT 4:8 ratio. On two occasions in the same normal control OKT8 cells fell below $20 \%$ - the highest value obtained in any patient with clinically definite multiple sclerosis in relapse. These findings make it unlikely that wide fluctuations in OKT8 cells or the OKT4:8 ratio occur in healthy 


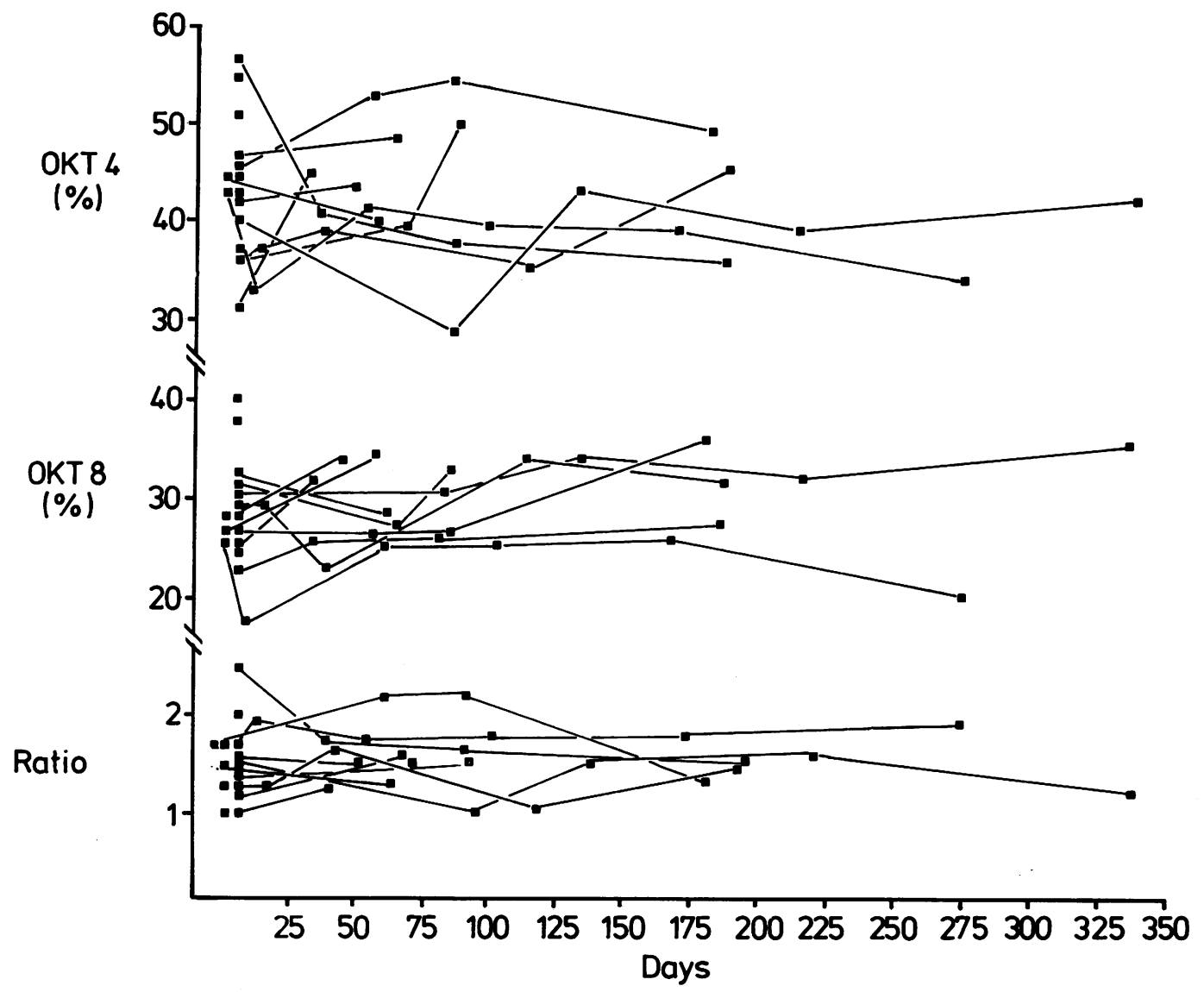

Fig 2 Number of OKT4, OKT8 cells (\%) and the OKT4:8 ratio in 14 controls studied randomly on 1 or multiple $(n=10)$ ioccasions for up to 340 days.

controls but this cannot be fully excluded by such infrequent sampling.

Longitudinal studies in patients with multiple sclerosis Lymphocyte subpopulation measurements were correlated with date of onset of symptoms in 10 patients with definite or suspected multiple sclerosis in relapse from Groups 2 or 3 and subsequently studied during their uncomplicated recovery for up to 65 days (fig 3 ). These results show that with some exceptions changes in lymphocyte subpopulations are most marked at the time of onset of symptoms and that there is a gradual return to normal within approximately one month. Several additional points should be made; patient " $a$ ", with optic neuritis and suspected multiple sclerosis, had a second episode of optic neuritis between the two samples which may account for the relatively low OKT8 cells (\%) observed on day 46. Patient "b" did not have reduced
OKT8 cells on either occasion; an attack of optic neuritis at onset was followed on day 38 by symptoms of a cervical cord lesion leading to her inclusion in Group 3. Patient "c", who had normal lymphocyte subpopulation levels, was studied once during an attack of optic neuritis but had a previous episode suggestive of optic nerve and brain stem demyelination 15 years previously at the age of 14 . Patients " $d$ " and " $e$ " made incomplete clinical recoveries despite return of lymphocyte subpopulations to normal. Patient " $f$ " showed no significant clinical improvement over the 65 days that lymphocyte subpopulations were studied.

Five patients with clinically definite multiple sclerosis and one suspected of having multiple sclerosis were judged to have had further relapses during the study. In all six, multiple samples were taken for up to 320 days after the presenting episode (fig 4). The observed changes in lymphocyte sub- 

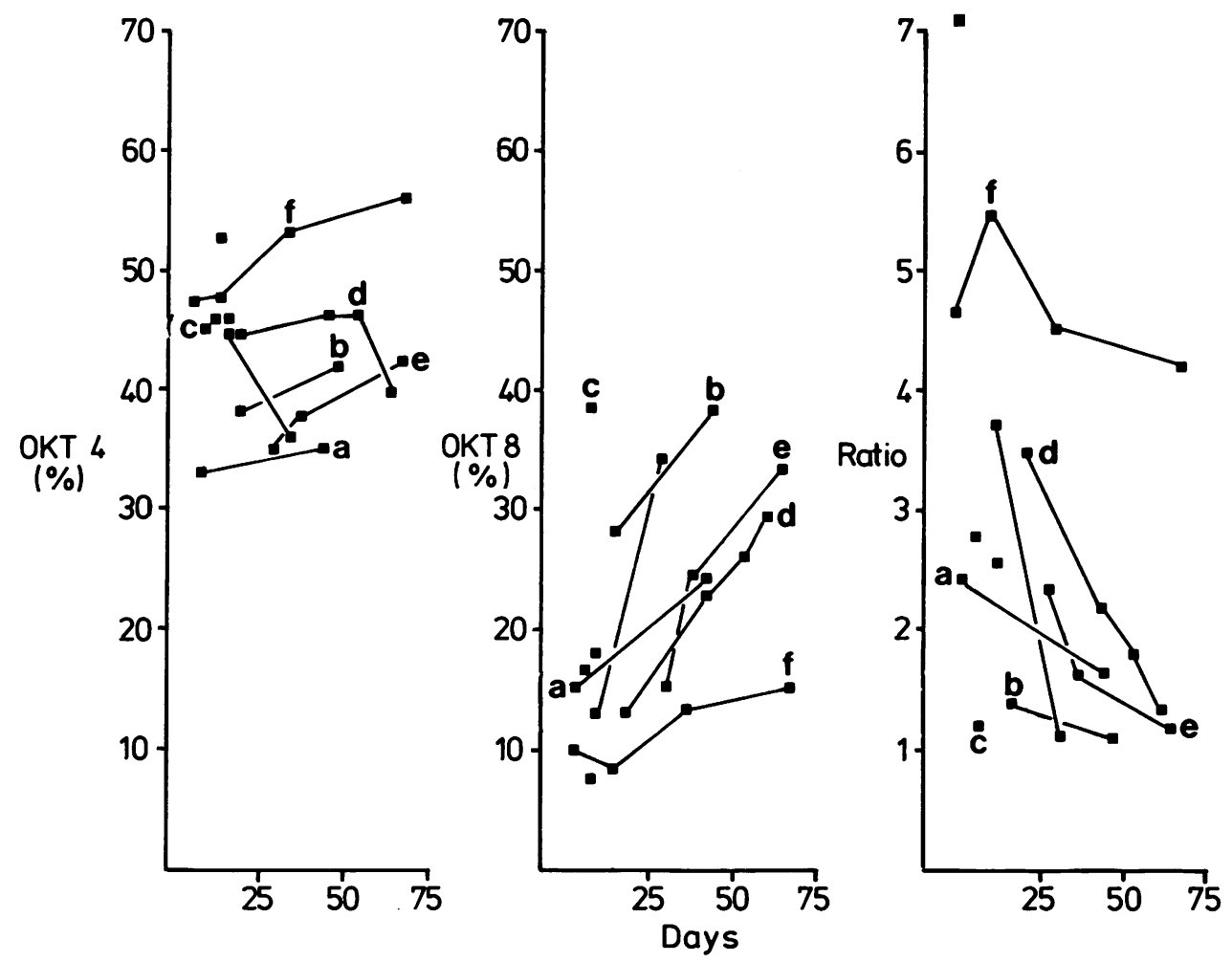

Fig 3 Numbers of OKT4, OKT8 cells (\%) and the OKT4:8 ratio in 10 patients with definite or suspected multiple sclerosis in relapse studied on one or multiple occasions during clinical recovery for up to 65 days after onset (day 0) of symptoms; $a, b, c, d, e$, and f refer to patients described in the text.

populations in these patients add to the evidence of a return to normal levels during periods of clinical remission and show that with the onset of fresh symptoms or signs OKT8 cells fall again. In three patients ("g", " $n$ " and "p") levels returned to the subnormal range seen in patients with clinically definite multiple sclerosis in relapse (Group 2); in two patients ("k" and " $\mathrm{m}$ ") studied 30 and 10 days after the onset of the second relapse, levels fell but not to the range seen in these same patients during their presenting episode. One other patient (" $h$ ") entered the study 100 days after the presenting episode and was studied for a further 160 days before his next relapse. OKT8 cells 14 days later were $20 \%$. In two patients (" $p$ " and " $n$ ") a decrease in OKT8 cells was demonstrated prior to the onset of new symptoms but in each patient the level had not returned to normal from the previous episode and residual signs were present which then increased.

The results of multiple sampling of peripheral blood lymphocyte subpopulations in a further four patients studied at intervals for up to 330 days are shown in fig 5. Two ("q" and "s") with clinically definite multiple sclerosis were studied after an episode of brain stem and optic nerve demyelination respectively; one (" $t$ ") had a recent episode of optic neuritis with symptoms over the previous seven years indicating a relapsing spinal cord lesion and the last patient ("u") had isolated optic neuritis only. These patients all made a complete symptomatic recovery from the presenting episode within 40 days and thereafter had no new or recurrent symptoms. However in each patient there was at least one subsequent fall in OKT 8 cells (to abnormal levels in three) accompanied in all cases by a rise in OKT4:8 ratio. Three patients (" $q$ ", " $s$ " and " $t$ ") could not be studied further to assess subsequent changes but the remaining patient ("u") had normal OKT8 cells and OKT4:8 ratio on only one occasion in $\mathbf{3 3 0}$ days.

Correlations between the date of onset of symptoms and lymphocyte subpopulations in 14 patients with optic neuritis not occurring in the context of clinically definite or suspected multiple sclerosis from Group 4, excluding patient " $u$ ", are shown in fig 6 . 


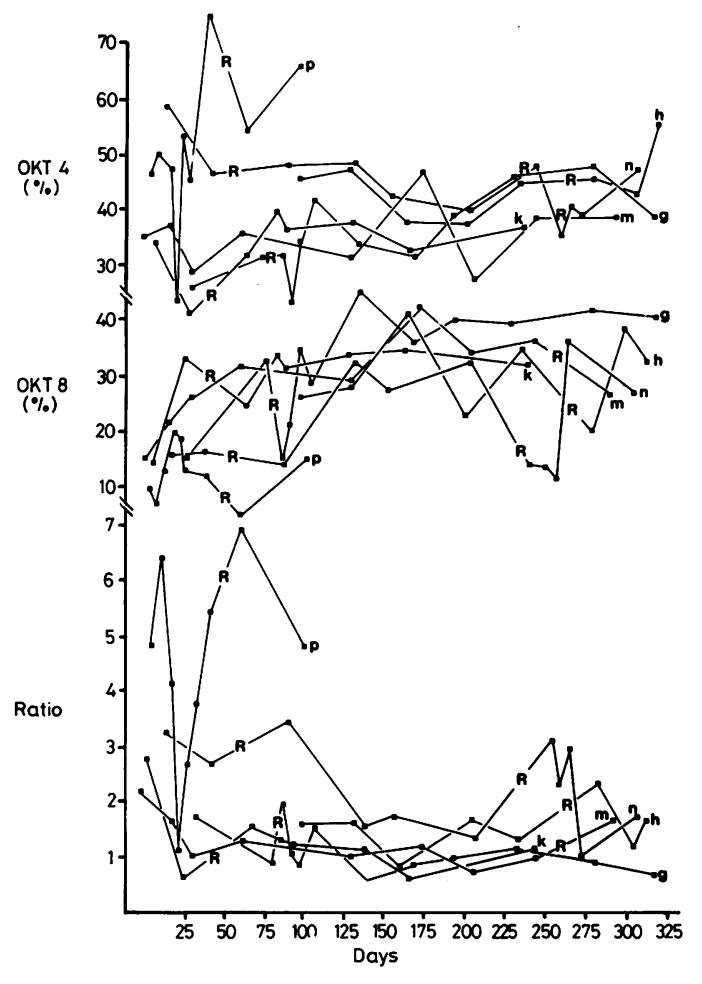

Fig 4 Numbers of OKT4, OKT8 cells (\%) and the OKT4:8 ratio in 6 patients with clinically definite or suspected multiple sclerosis studied on multiple occasions after the onset of new symptoms (day 0) in each of whom at least one subsequent relapse occurred during the next 325 days. $R$ indicates the day of onset of the relapse and where two or more lines overlap, relates to the broken line; $g, h, k, m, n$ and $p$ identify the patients so that comparisons can be made between sections of fig 4 and the text.

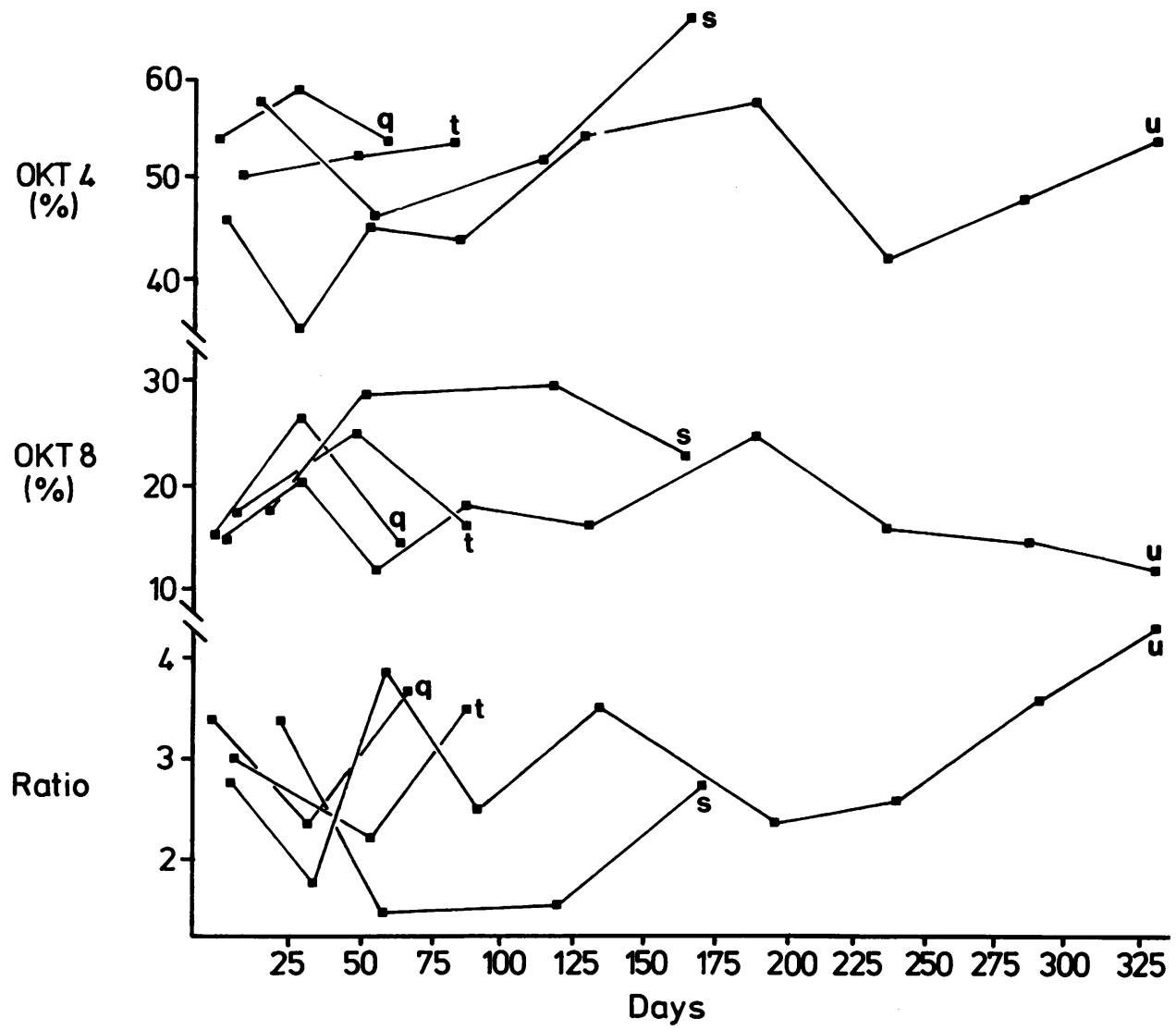

Fig 5 Numbers of OKT4, OKT8 cells (\%) and the OKT4:8 ratio in 4 patients recovering from an episode of demyelination for up to 325 days after the onset of symptoms in whom further lymphocyte changes occurred without associated clinical symptoms; $q, s, t$ and $u$ identify patients referred to in the text. 

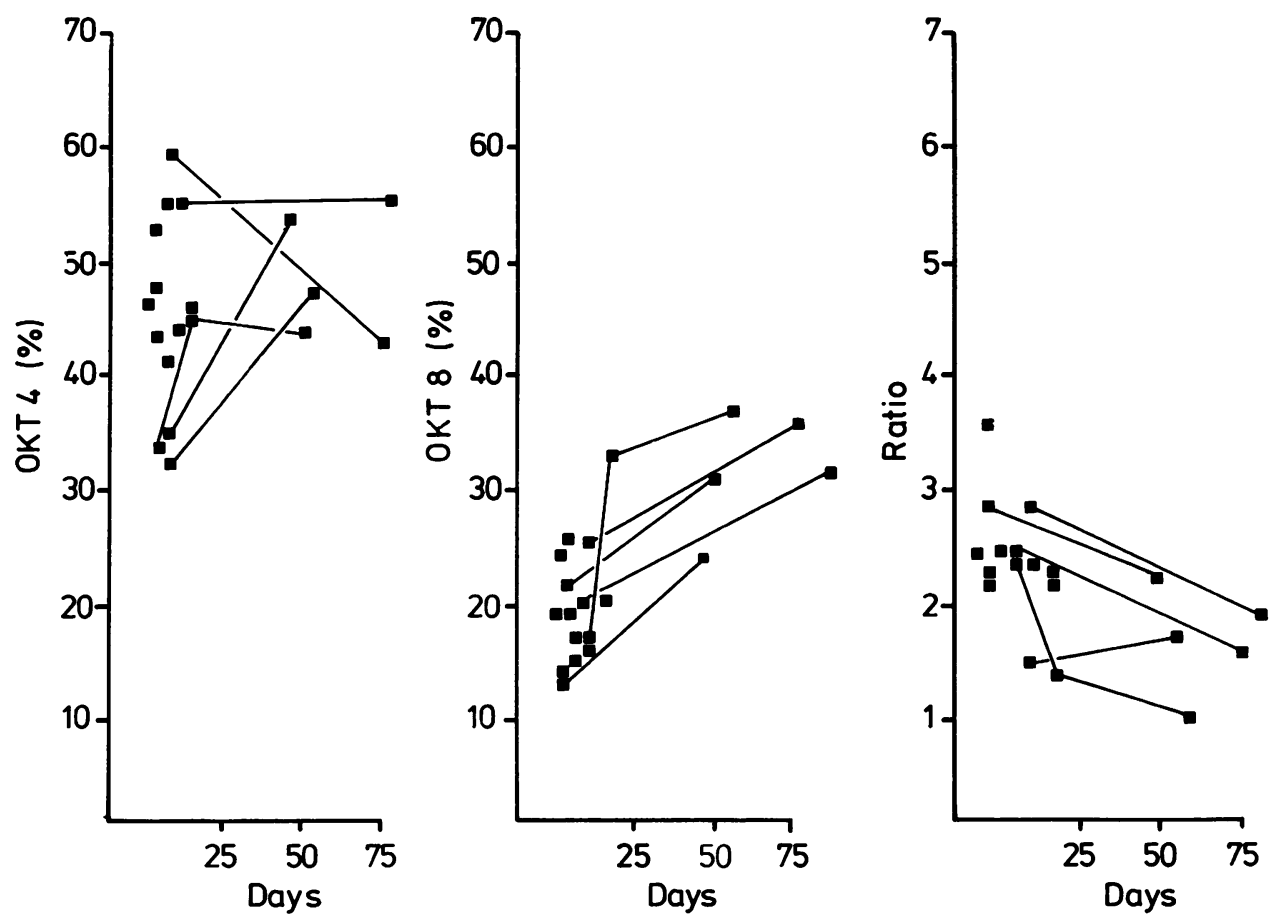

Fig 6 Numbers of OKT4, OKT8 cells (\%) and the OKT4:8 ratio in 14 patients with isolated optic neuritis studied singly or on two occasions for up to 78 days after the onset of visual symptoms (day 0 ).

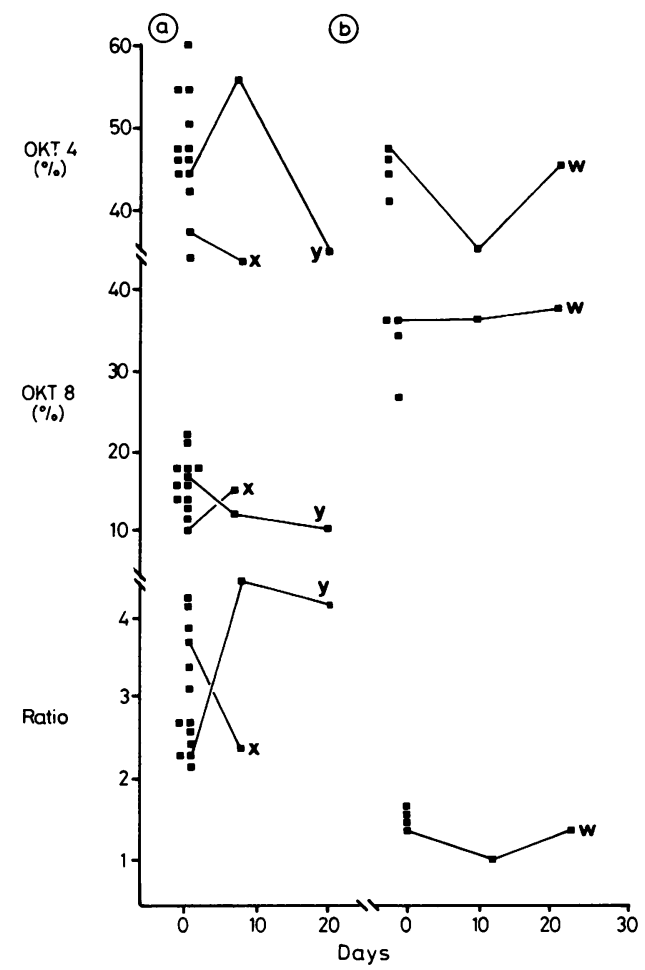

Fig 7 Numbers of OKT4, OKT8 cells (\%) and the OKT4:8 ratio in 17 patients with progressive multiple sclerosis; column (a) refers to single or multiple samples in 13 patients with low levels of OKT8 cells or a high OKT4:8 ratio and column $(b)$ refers to four patients with normal levels on single or multiple samples. $w, x$ and $y$ refer to patients described in the text. 
The results show low levels of OKT8 cells and high OKT4:8 ratios in some patients studied close to the onset of symptoms but others had higher levels in the earliest sample. In all five patients, studied on more than one occasion, OKT8 cells and the OKT4:8 ratio returned partly or completely to normal. Reductions in OKT8 cells occur in isolated optic neuritis but not to the same level as in multiple sclerosis patients with relapses affecting non-visual pathways.

Single observations in 17 patients with progressive multiple sclerosis showed subnormal $(11 / 17,65 \%)$, normal $(4 / 17,23 \%)$ and intermediate $(2 / 17,12 \%)$ levels (fig 7) indicating that a fixed or slowly progressive deficit may or may not be accompanied by changes in lymphocyte subpopulations associated with disease activity in patients with relapsing and remitting multiple sclerosis. Repeat sampling in three patients ("w", " $x$ " and " $y$ ") showed that one ("w") remained normal on further occasions, one with subnormal levels increased (" $x$ ") and one fell further (" $y$ ") but in all three no change in their fixed neurological disability could be detected clinically.

Short courses of treatment with steroids by injection, given to some patients during relapse, are not shown in the figures.

\section{Discussion}

This study confirms previous reports that patients with multiple sclerosis in relapse have low levels of OKT 8 cells and a high OKT4:8 ratio and shows that the abnormality returns to normal in approximately one month from the onset of symptoms; further changes occur with new relapses. In $25 \%$ of patients abnormalities of lymphocyte populations occur unaccompanied by new symptoms or signs; fluctuations of this kind do not occur in controls.

Most individuals were studied once every four to six weeks and the findings probably under-estimate the absolute level to which OKT8 cells fall during relapse, the timing of this change in relation to onset of symptoms and the frequency with which clinically silent fluctuations occur. In the only other detailed longitudinal study ${ }^{14}$ lymphocyte subpopulations were measured at weekly intervals in six patients with multiple sclerosis and four controls for six months. Two patients had no relapses during this period and OKT4:8 ratios were normal on each occasion. One patient was judged to have had two new episodes during the study; the first lasted six weeks and OKT4:8 ratios were high on three of the first four occasions and remained normal as symptoms recovered. A subsequent rise in OKT4:8 ratio preceded the next relapse by five days. Another patient had abnormal lymphocyte subpopulations during two relapses, preceding symptoms by seven days in one instance, but four other episodes of recurrent neurological symptoms (which did not necessarily indicate a new relapse) were not accompanied by peripheral blood changes. One patient with a rapidly accumulating deficit during the study had elevated OKT4:8 ratios on 12/27 occasions; although a rise in ratio preceded new symptoms on two occasions no exact correlation with clinical symptoms could be made. A further patient with progressive multiple sclerosis had an elevated OKT4:8 ratio in each of 20 samples.

The results in both longitudinal studies and single observations in groups of patients with multiple sclerosis in relapse indicate therefore that a decrease in OKT8 cells is usually but not invariably associated with clinically evident disease activity in multiple sclerosis. It is important to determine whether this change is causally related to relapses or whether it is an epiphenomenon.

The observation that changes in lymphocyte subpopulations preceded the onset of new symptoms in $7 / 38(18 \%)$ relapses occurring in 18 patients included in this report or those studied by Hauser et $a l^{14}$ and the poor correlation between clinical recovery and return of OKT cells to normal both suggest that the changes reflect an alteration in immune regulation that itself leads to immunologically mediated tissue damage.

Circulating T lymphocytes consist of two main subpopulations, helper and suppressor cells; each probably contain functional subsets. Helper cells respond to antigen presented by other specialised cells, in association with the HLA-DR gene products common to both the responding cell and the antigenpresenting cell. Helper cells induce $\mathrm{T}$ cell mediated immune responses, $\mathrm{B}$ cell antibody production and, if HLA gene sharing is present, they stimulate suppressor cells. In turn the suppressor subset reduces helper and B cell activity directly and through soluble factors. This subset also includes cytotoxic cells, which recognise target antigens in association with HLA-A, B and C gene products. ${ }^{15}$ The monoclonal antibody OKT8 identifies the cytotoxic/ suppressor subpopulation and the alteration in OKT8 cells could reflect a decrease in one or other. In fact there is independent evidence for a decrease in suppressor function in patients with active multiple sclerosis. The suppressor effect of Concanavalin A (Con A) stimulated T lymphocytes on the response of autologous cells to further Con A stimulation is impaired during disease activity, rebounds during recovery and falls to subnormal levels when the disease is stable. ${ }^{16-18}$ Although Con A stimulated lymphocytes, $T_{G}$ and OKT8 cells are each thought to have suppressor activity in immune regulation there is a poor correlation between OKT8 and $T_{G}$ cells suggesting that the latter population is heterogenous 
and contains few T cells. 81619

A separate problem is whether the reduction in OKT8 cells is due to a decrease in number, temporary alteration in expression of cell surface antigens or re-distribution of these cells into the CNS. The pattern of staining by OKT monoclonal antibodies of lymphocytes infiltrating early multiple sclerosis plaques has not been reported but it is unlikely, even if these were OKT8 cells, that the numbers required to produce a change in circulating levels from $29-14 \%$ could be accommodated in the few plaques underlying each new relapse. Although $\mathrm{T}$ cells are increased in CSF during relapse the peripheral blood changes in lymphocyte subpopulations are not reflected in the CSF. Neither OKT4, OKT8 cells nor their ratio alter but OKT4 cells are increased in progressive cases compared to patients in relapse or controls. ${ }^{2021}$

If changes in lymphocyte subpopulations do precipitate relapses in multiple sclerosis one hypothetical mechanism is that CNS damage is mediated by stimulated $\mathrm{T}$ helper sells which amplify antibody and cell mediated immune responses against CNS antigens, but which are usually kept inactive by suppressor cells; periodically, non-specific events such as coincidental infections could disturb the balance of helper and suppressor cells allowing the helper population to expand, leading to tissue damage, until equilibrium is re-established.

An alternative explanation is that the decrease in OKT8 cells and suppressor function is the result, not the cause, of CNS damage in multiple sclerosis. There is cross reactivity between suppressor lymphocytes and isolated sheep oligodendrocytes in culture using OKT8 monoclonal antibody, and rat antisheep oligodendrocyte serum, absorbed with human red blood cells, binds to a small percentage of (OKT unidentified) human lymphocytes so that the changes in peripheral blood could be a non specific effect of primary oligodendrocyte damage..$^{22} 23$

In addition, reductions in OKT8 cells are not specific to multiple sclerosis. Decreases have been observed in other diseases ${ }^{24} 25$ and were found in the present group of patients with isolated optic neuritis, not all of whom will progress to develop multiple sclerosis. ${ }^{26}$ Two patients with isolated optic neuritis who have already developed evidence of more widespread demyelination had normal OKT8 cells during the presenting episode of optic neuritis emphasising that abnormal lymphocyte populations are unlikely to be a useful method for distinguishing different categories of optic neuritis.

The decrease in OKT8 cells may, however, be useful in the management of patients with established multiple sclerosis since the clinical method does not provide reliable evidence for activity of the pathological process underlying the disease. It is well known that in patients with relapsing/remitting disease, electrophysiological and imaging techniques can identify lesions which are not clinically apparent by nature of their size or position. In patients with a fixed deficit in whom the pathway subserving a particular function is already blocked a new lesion may produce no additional symptoms or signs. In addition histological observations ${ }^{27} 28$ and the fact that IgG synthesis in patients with multiple sclerosis continues throughout the disease ${ }^{29}$ suggests that there is chronic low grade pathological activity even during clinical remission. Taken together this evidence is consistent with the idea that changes in OKT8 cells seen in patients with relapsing and remitting or progressive multiple sclerosis are markers of new lesions even when not associated with a change in symptoms or signs.

There is some evidence that disability and frequency of relapse improve after prolonged immunological treatment given to mildly affected patients. ${ }^{30}$ Serial sampling of lymphocyte subpopulations in association with evoked potential and imaging techniques could be used to quantitate all new plaques and identify patients at risk of significant disability before such time as lesions had accumulated to produce a fixed deficit. These patients would be ideal candidates for more detailed clinical assessment and laboratory monitoring of immunological treatment in multiple sclerosis.

This study was supported by grants from the Medical Research Council. I am grateful to Professor RW Gilliatt and Professor WI McDonald for allowing me to study their patients and to Professor WI McDonald for his helpful discussion of this paper.

\section{References}

1 Hughes RAC, Gray IA, Gregson NA, Metcalfe RA. Multiple sclerosis-yymphocyte transformation with multiple sclerosis and normal brain myelin basic protein and subcellular fractions. Acta Neurol Scand 1982;65:161-73.

2 Cook SD, Dowling PC. Multiple sclerosis and viruses; an overview. Neurology (Minneap) 1980;30:80-91.

3 Lisak RP, Levinson AI, Zweiman B, Abdou NI. T and B lymphocytes in multiple sclerosis. Clin Exp Immunol 1975;22:30-4.

4 Allen JC, Sheremata W, Cosgrove JBR, Osterland K, Shea $M$. Cerebrospinal fluid $T$ and $B$ lymphocyte kinetics related to exacerbations of multiple sclerosis. Neurology (Minneap) 1976;26:579-83.

5 Naess A, Nyland H. Multiple sclerosis: T lymphocytes in cerebrospinal fluid and blood. Eur Neurol 1978;17:616.

6 Turner A, Cuzner ML, Davison AN, Rudge P. On the role of sensitised $\mathrm{T}$ lymphocytes in the pathogenesis of 
multiple sclerosis. J Neurol Neurosurg Psychiatry 1980;43:305-9.

7 Kam-Hansen K. Reduced number of active $\mathrm{T}$ cells in cerebrospinal fluid in multiple sclerosis. Neurology (Minneap) 1979;29:897-9.

${ }^{\curlyvee}$ Huddlestone JR, Oldstone MBA. T suppressor $\left(T_{G}\right)$ lymphocytes fluctuate in parallel with changes in the clinical course of patients with multiple sclerosis. $J$ Immunol 1979;123:1615-8.

9 Coyle PK, Hirsch RL, O'Donnell P et al. Cerebrospinal fluid lymphocyte populations and immune complexes in active multiple sclerosis. Lancet 1980;ii:229-32.

10 Traugott V, Scheinberg LC, Raine CS. Multiple sclerosis: heterology among early $\mathrm{T}$ cells and $\mathrm{T}_{\mathrm{G}}$ cells. Ann Neurol 1982;11:182-6.

11 Reinherz EL, Weiner HL, Hauser SL, Cohen JA, Distaso JA, Schlossman SF. Loss of suppressor T cells in active multiple sclerosis. New Engl J Med 1980;303:124-9.

12 Bach M-A, Tournier E, Phan-Dinh-Tuy F, Chatenoud L, Bach J-F. Deficit of suppressor T cells in active multiple sclerosis. Lancet 1980;ii:1221-3.

13 McDonald WI, Halliday AM. Diagnosis and classification of Multiple Sclerosis. In: Multiple Sclerosis. Br Med Bull 1977;33:(1) 4-8.

14 Hauser SL, Reinherz EL, Hoban CJ, Schlossman SF, Weiner HL. Immunoregulatory T-cells and lymphocytotoxic antibodies in active multiple sclerosis; weekly analysis over a six month period. Ann Neurol 1983 (in press).

15 Editorial. T. Lymphocytes. Lancet 1982;i:778-9.

16 Antel JP, Weinrich M, Arnason BGW. Mitogen responsiveness and suppressor cell function in multiple sclerosis. Neurology (Minneap) 1978;28:999-1003.

17 Antel JP, Arnason BGW, Medof ME. Suppressor cell function in multiple sclerosis: correlation with clinical disease activity. Ann Neurol 1979;5:338-42.

18 Sheremata WA, Rzepiela AJ, Sazant A, Berger J. Confirmation of concanavalin A (Con A) inducible suppressor cell function in multiple sclerosis (abstract). Neurology (Minneap) 1982;32: A145.

19 Reinherz EL, Moretta L, Roper M. Human T lymphocyte subpopulations defined by Fc receptors and monoclonal antibodies. J Exp Med 1980;151:96974.

20 Oger J, Antel JP, Noronha A, Arnason BGW. Changes in $T$ cell subpopulations in the cerebrospinal fluid of multiple sclerosis patients (abstract). Neurology (NY) 1982;32: A148.

21 Hauser SL, Reinherz EL, Hoban CJ, Schlossman SF, Weiner HL. CSF cells in multiple sclerosis: monoclonal antibody analysis and relationship to peripheral blood T-cells. Neurology (NY) 1983 (in press).

22 Oger J, Szuchet S, Antel JP, Arnason BGW. A monoclonal antibody against human $T$ suppressor lymphocytes binds specifically to the surface of cultured oligodendrocytes. Nature 1982;295:66-8.

23 Oger J, Dumas M, Szuchet S, Antel JP, Arnason BGW. Generation of anti T-cell antibodies using oligodendrocytes (abstract). Neurology (NY) 1982; 32:A 86.

24 Reinherz EL, Schlossman SF. Regulation of the immune response-inducer and suppressor $\mathrm{T}$ lymphocyte subsets in human beings. New Engl J Med 1980;303:370-3.

25 Routhier G, Janossy G, Epstein O, Thomas HC, Sherlock S, Kung PC, Goldstein G. Effects of Cyclosporin $A$ on suppressor and inducer $T$ lymphocytes in primary biliary cirrhosis. Lancet 1980;ii:1223-6.

26 Compston DAS, Batchelor JR, Earl CJ, McDonald WI Factors influencing the risk of multiple sclerosis developing in patients with optic neuritis. Brain 1978;101:495-511.

27 Prineas JW, Connell F. The fine structure of chronically active multiple sclerosis plaques. Neurology (Minneap) 1978;28:(2)68-75.

28 Prineas JW, Wright RG. Macrophages, lymphocytes and plasma cells in the perivascular compartments in chronic multiple sclerosis. Laboratory Investigation 1978;38:409-21.

29 Olsson J, Nilsson K. Gamma globulins of CSF and serum in multiple sclerosis: isoelectric focussing on polyacrylamide gel and agar gel electrophoresis. Neurology (Minneap) 1979;29:1383-91.

30) Editorial. Immunological treatment in multiple sclerosis. Lancet 1980;ii:953-4. 